\title{
Insight into the Real Efficacy of Graphene for Enhancing Photocatalytic Efficiency: A Case Study on CVD Graphene- $\mathrm{TiO}_{2}$ Composite
}

Zhuquan Huang, a, Jiaqi Wang, b, ${ }^{*}$ Suwei Lu, ${ }^{a}$ Hun Xue, ${ }^{a}$ Qinghua Chen, ${ }^{a}$ Min-Quan Yang, a, * Qingrong Qian ${ }^{\text {a, * }}$

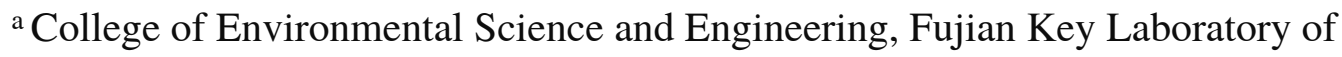
Pollution Control \& Resource Reuse, Fujian Normal University, Fuzhou, Fujian 350007, P. R. China

b State Key Laboratory of Photocatalysis on Energy and Environment, College of Chemistry, Fuzhou University, Fuzhou 350116, Fujian, P. R. China

$\ddagger$ Zhuquan Huang and Jiaqi Wang contributed equally to this work.

Corresponding author: Min-Quan Yang, Qingrong Qian

*E-mail address: yangmq@,fjnu.edu.cn (Min-Quan Yang).

*E-mail address: qrqian@fjnu.edu.cn (Qingrong Qian). 


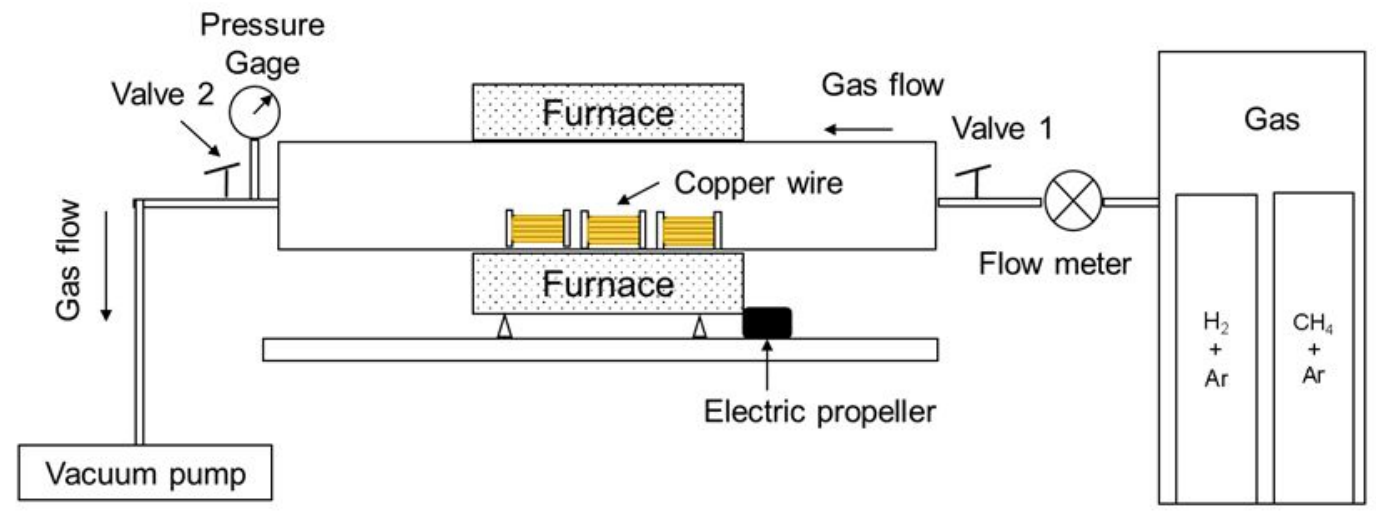

Figure S1. The schematic view of the CVD method.
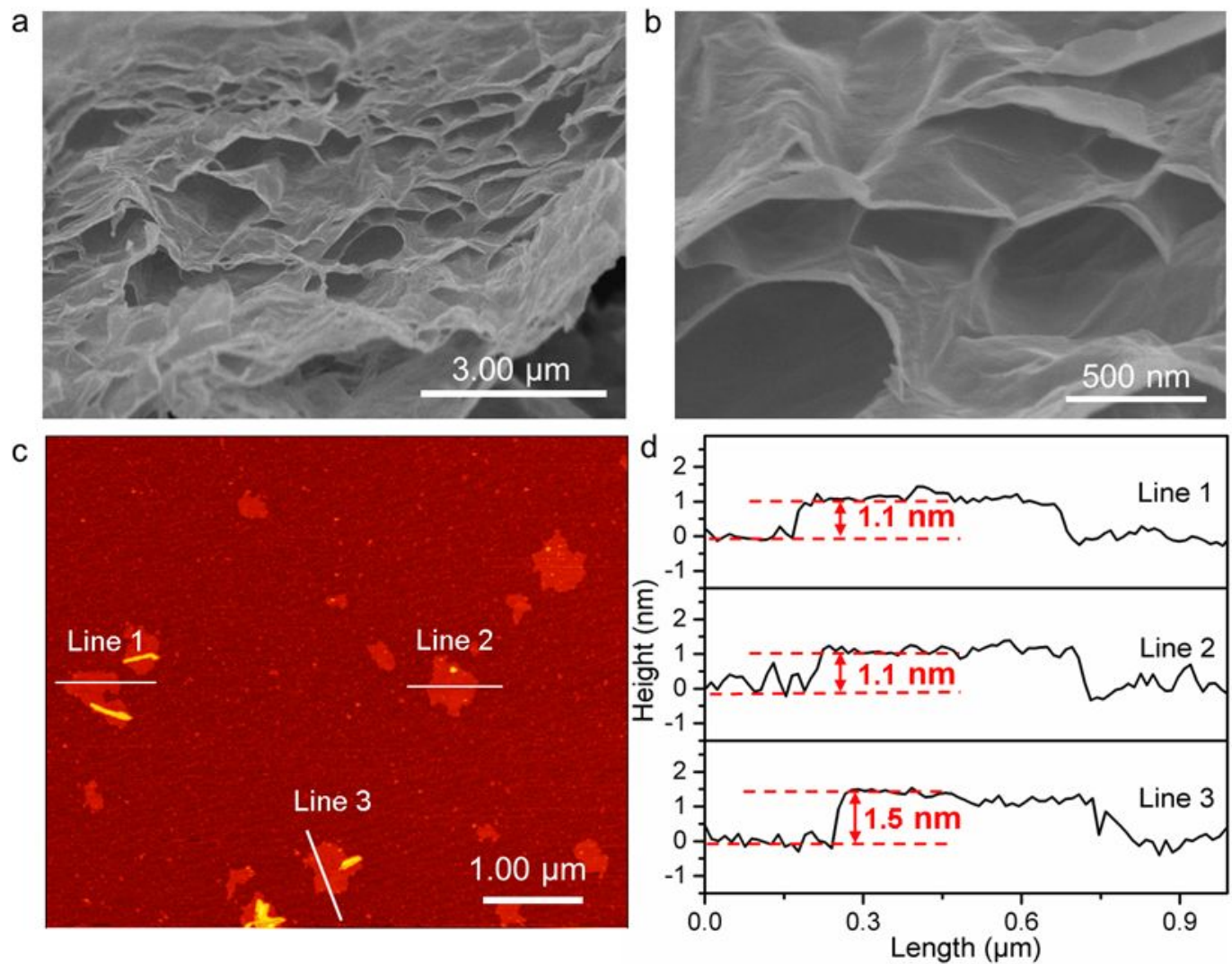

Figure S2. (a, b) SEM images of RGO, (c) AFM image and (d) the height profile for the obtained RGO. 


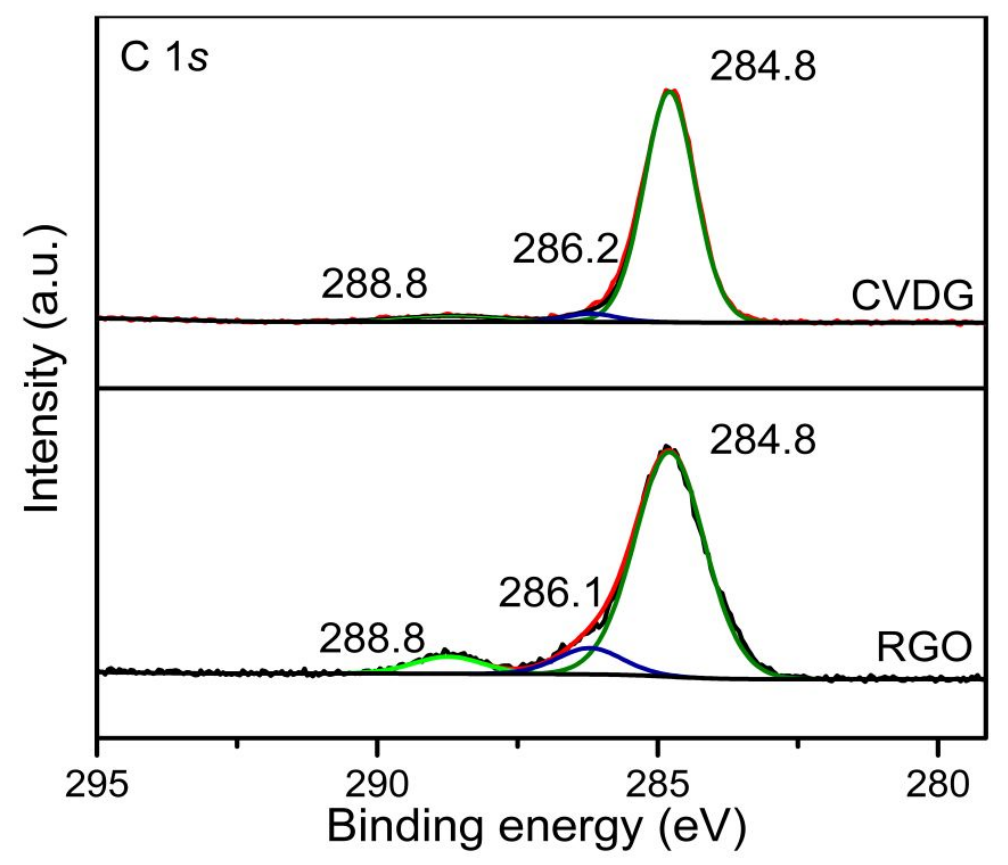

Figure S3. The high-resolution XPS spectra of C 1s for RGO and CVDG.

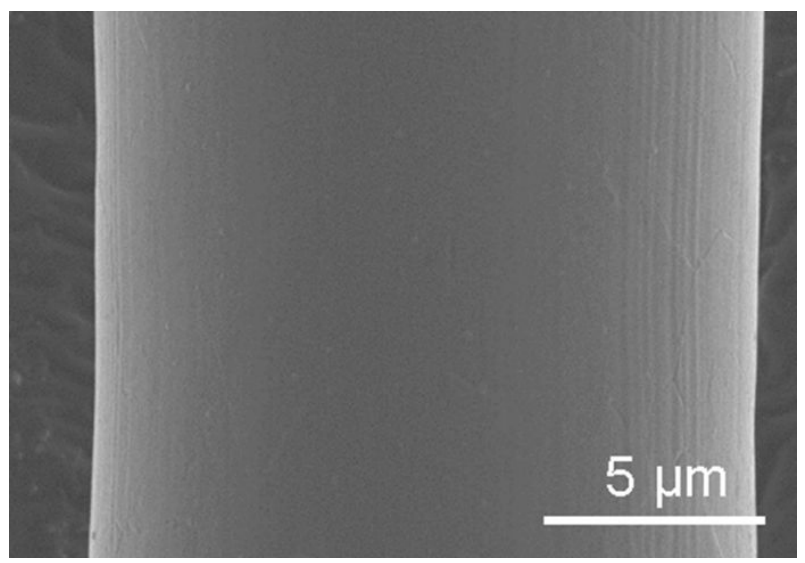

Figure S4. SEM image of $\mathrm{Cu}$ wire. 


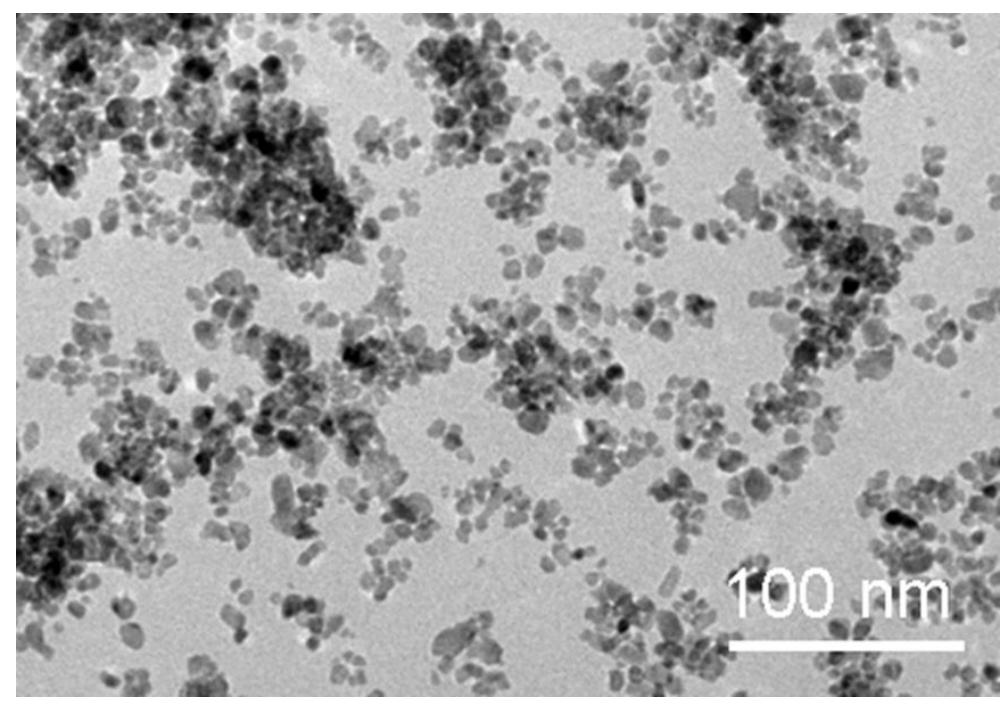

Figure S5. TEM image of $\mathrm{TiO}_{2}$.

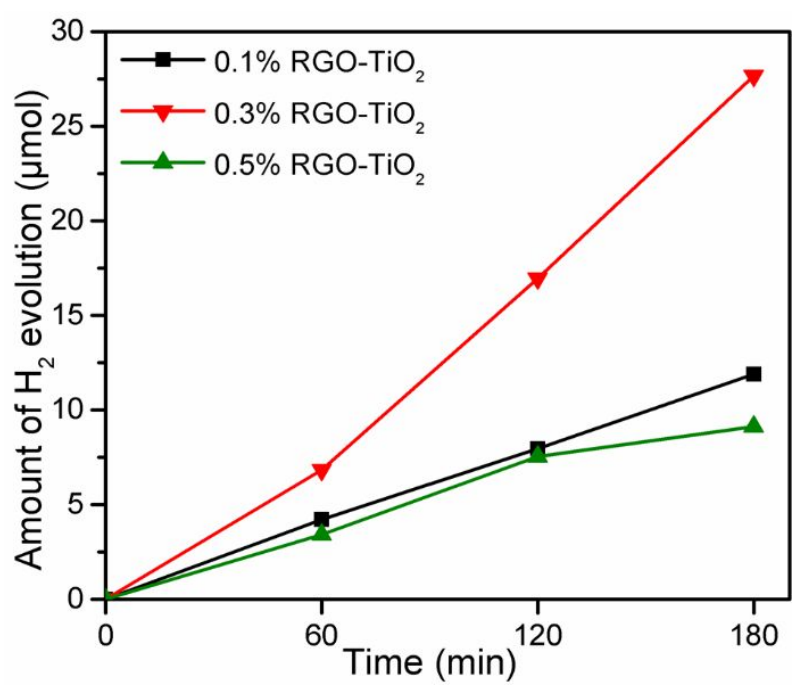

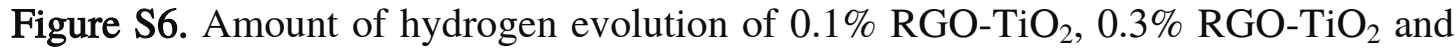
$0.5 \% \mathrm{RGO}-\mathrm{TiO}_{2}$. 

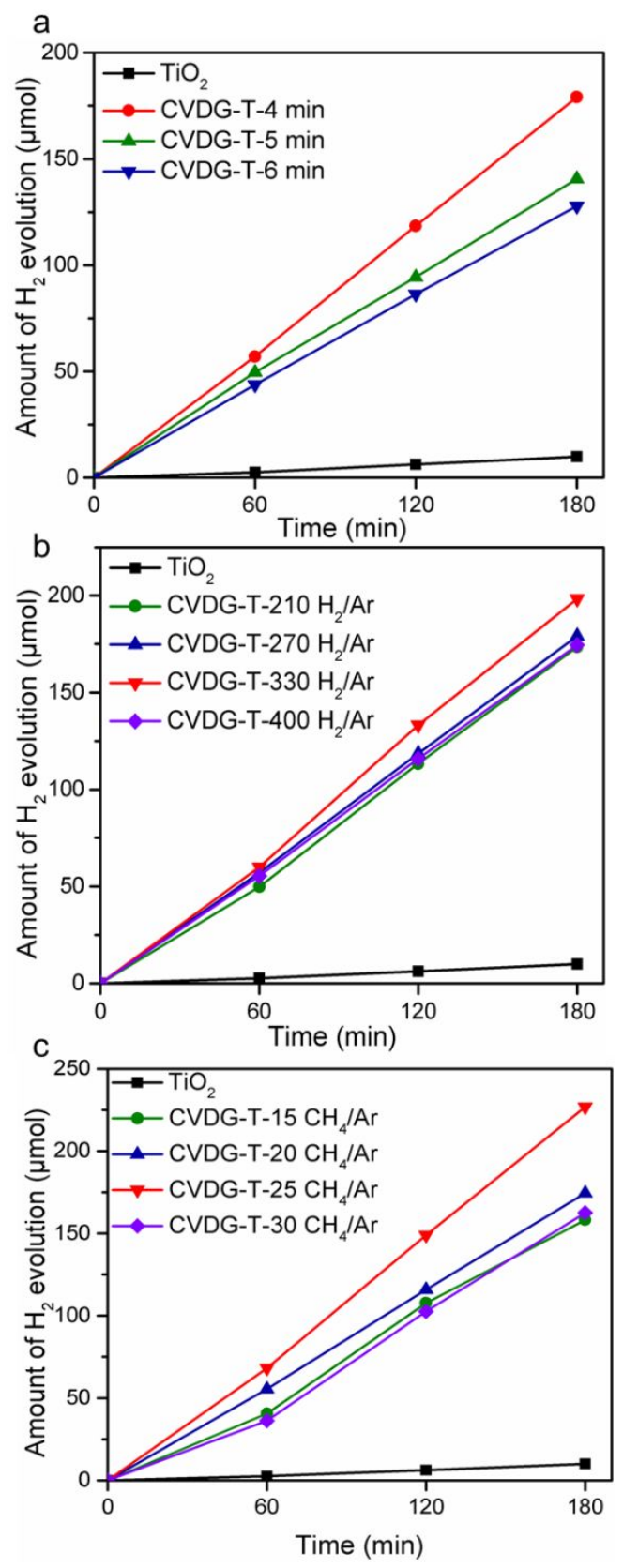

Figure S7. (a) Amount of hydrogen evolution of CVDG-TiO ${ }_{2}$ obtained at different growth times: 4 min, 5 min and 6 min; (b) amount of hydrogen evolution of CVDG$\mathrm{TiO}_{2}$ fabricated at different $\mathrm{H}_{2}$-Ar flow rates (the growth time is 4 min):210, 270, 330, and $400 \mathrm{~mL} \mathrm{~min}-1$; (c) amount of hydrogen evolution of CVDG- $\mathrm{TiO}_{2}$ fabricated at different $\mathrm{CH}_{4}$-Ar flow rates (the growth time is $4 \mathrm{~min}$ and the $\mathrm{H}_{2}$ - $\mathrm{Ar}$ flow rates is 330 $\left.\mathrm{mL} \min ^{-1}\right): 15,20,25$, and $30 \mathrm{~mL} \mathrm{~min}^{-1}$. 

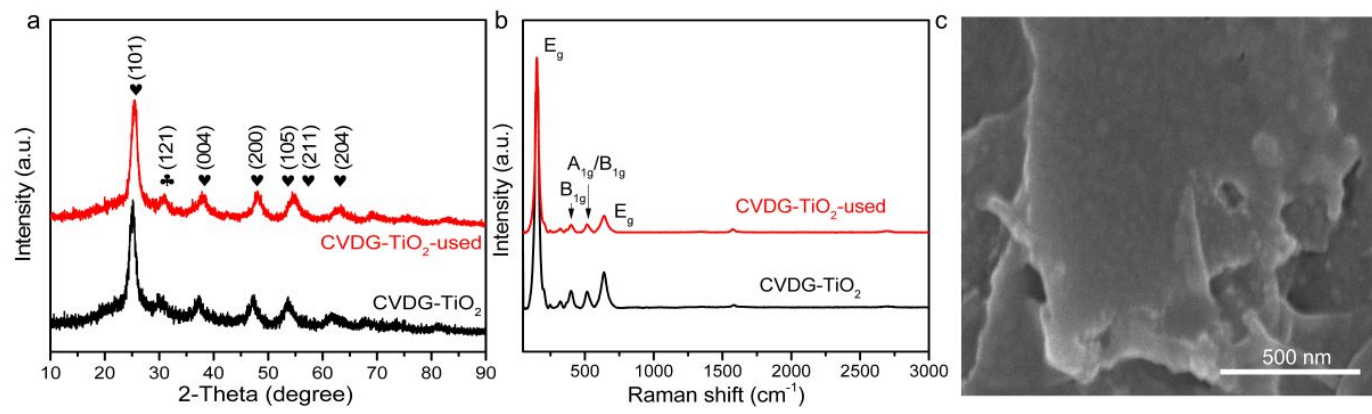

Figure S8. (a) XRD patterns, (b) Raman spectra of CVDG- $\mathrm{TiO}_{2}$ and $\mathrm{CVDG}-\mathrm{TiO}_{2}$-used, and (c) SEM image of CVDG- $\mathrm{TiO}_{2}$-used.

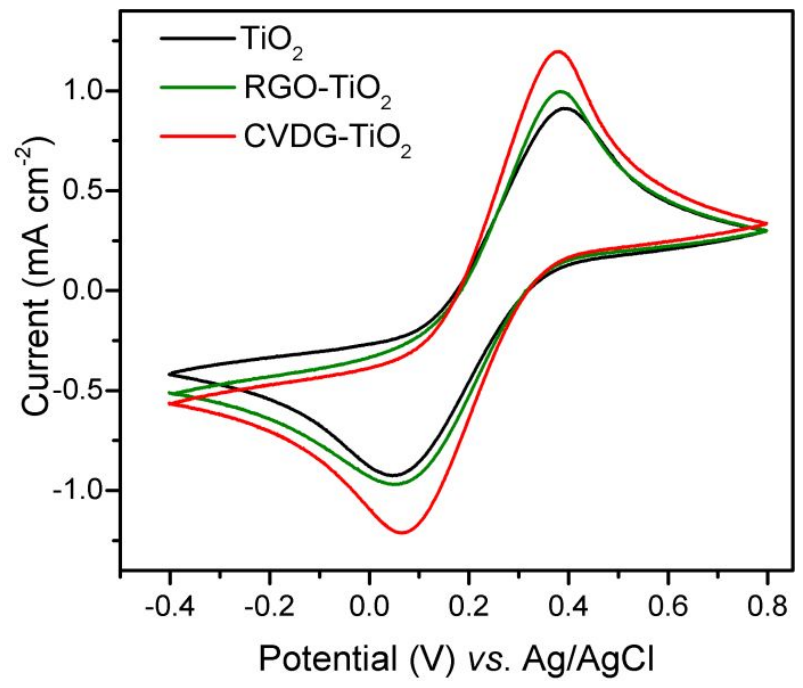

Figure S9. Cyclic voltammograms of $\mathrm{TiO}_{2}, \mathrm{RGO}-\mathrm{TiO}_{2}$, and CVDG-TiO 2 composites. 


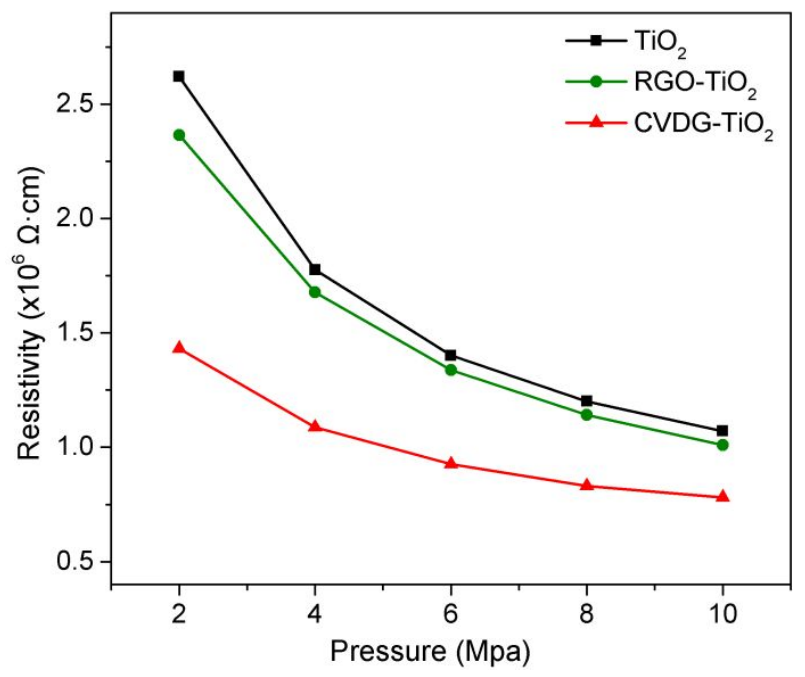

Figure S10. The resistivity test of $\mathrm{TiO}_{2}, \mathrm{RGO}-\mathrm{TiO}_{2}$, and CVDG-TiO 2 samples under various pressures.

Table S1. The specific BET surface areas, total pore volume and mean pore diameter of $\mathrm{TiO}_{2}, \mathrm{RGO}-\mathrm{TiO}_{2}$ and CVDG-TiO 2 .

\begin{tabular}{|c|c|c|c|}
\hline Samples & $\mathrm{S}_{\mathrm{BET}}\left(\mathrm{m}^{2} / \mathrm{g}\right)$ & Total pore volume $\left(\mathrm{cm}^{3} / \mathrm{g}\right)$ & Mean pore diameter $(\mathrm{nm})$ \\
\hline $\mathrm{TiO}_{2}$ & 122.7 & 0.24 & 7.8 \\
\hline $\mathrm{RGO}-\mathrm{TiO}_{2}$ & 130.3 & 0.22 & 6.7 \\
\hline $\mathrm{CVDG}-\mathrm{TiO}_{2}$ & 111.6 & 0.19 & 6.8 \\
\hline
\end{tabular}

